\title{
Rate Evalution of Graft Copolymerization of Hydrophilic Monomers onto Natural Polymer
}

\author{
HOSSEIN SADEGHI*, SAHAR MIRDARIKVANDE, ANAHITA GODARZI, \\ MALEYHE ALAHTARI, HADIS SHASAVARI and LALEH MANSOURI
}

\author{
Department of Chemistry, Science Faculty, Islamic Azad University, \\ Khorramabad Branch, Khorramabad, Iran. \\ ${ }^{*}$ Corresponding author E-mail: hhossein252@yahoo.com \\ http://dx.doi.org/10.13005/ojc/300142
}

(Received: December 25, 2013; Accepted: January 29, 2014)

\begin{abstract}
In this research, to follow synthesis of a graft copolymer based on alginate via graft copolymerization hydrophilic monomers onto alginate backbones, kinetic polymerization and it,s relationship with effective parameters were investigated. According to the empirical rates of the polymerization and the graft copolymerization of AAm and AMPS onto alginate backbone, the overall activation energy of the graft copolymerization reaction was estimated to be $33.40 \mathrm{~kJ} / \mathrm{mol}$.
\end{abstract}

Key words: Alginate, Graft, Copolymer, Hydrophilic monomers, Kinetic polymerization.

\section{INTRODUCTION}

During the past decades, considerable research was being carried out on the graft copolymerization of hydrophilic and hydrophobic vinyl monomers onto polysaccharides. These biodegradable and low cost graft copolymers, with new properties, can be used in many applications such as textiles, paper industry, agriculture, medical treatment and also in petroleum industry as flocculants and thickening agents(1-4). Free radical graft copolymerization was usually carried out by using various initiators such as ammonium persulfate, benzoyl peroxide and azoisobutyronitrile. The modification of natural polymers is a promising method for the preparation of new materials ${ }^{1-3}$. An efficient approach to modify of natural polymers, in order to synthesis of natural-based SAPs, is graft polymerization of vinylic monomers onto their backbones in the presence of crosslinkers. Free radical graft copolymerization with various monomers can carried out with different initiator systems ${ }^{4-6}$. In the present report, to modify the alginate, the grafting of Acrylamide (AAm) and 2-Acrylamido-2-methyl propan solfonic acid (AMPS) onto alginate chains in the presence of ammonium persulfate (APS) as an initiator was performed in a homogeneous system and dependence of kinetic polymerization with effective parameters were investigated. 


\section{EXPERIMENTAL}

\section{Materials}

Sodium alginate (chemical grade, MW 50000), ammonium persulfate (APS, from Fluka), acrylamide(AAm, from Merck), 2-acrylamido-2methylpropanesulfonic acid (AMPS, from Merck), were used without further purification. All other chemicals were also analytical grade. Double distilled water was used for the hydrogel preparation and swelling measurements.

\section{RESULTS AND DISCUSSION}

\section{Synthesis, mechanism and reaction rate}

A general reaction mechanism for graft copolymerization of AAm and AMPS monomers onto alginate backbones in the presence of APS initiator is shown in Scheme 1. The sulfate anionradical produced from thermally decomposition of APS, abstracts hydrogen from one of the functional groups in side chains (i.e. $\mathrm{COOH}, \mathrm{SH}, \mathrm{OH}$, and $\mathrm{NH}_{2}$ ) of the substrate to form corresponding radical[3]. The mixture monomers, which are in vicinity of the macroradical sites, become acceptor of alginate radicals resulting in chain initiation and thereafter themselves become free radical donor to the neighboring molecules leading to propagation. These grafted chains are terminated by coupling to give the graft copolymer ${ }^{5}$.

A general reaction mechanism for graft copolymerization reaction, in analogy with that previously mentioned may be as follows (Scheme 1):
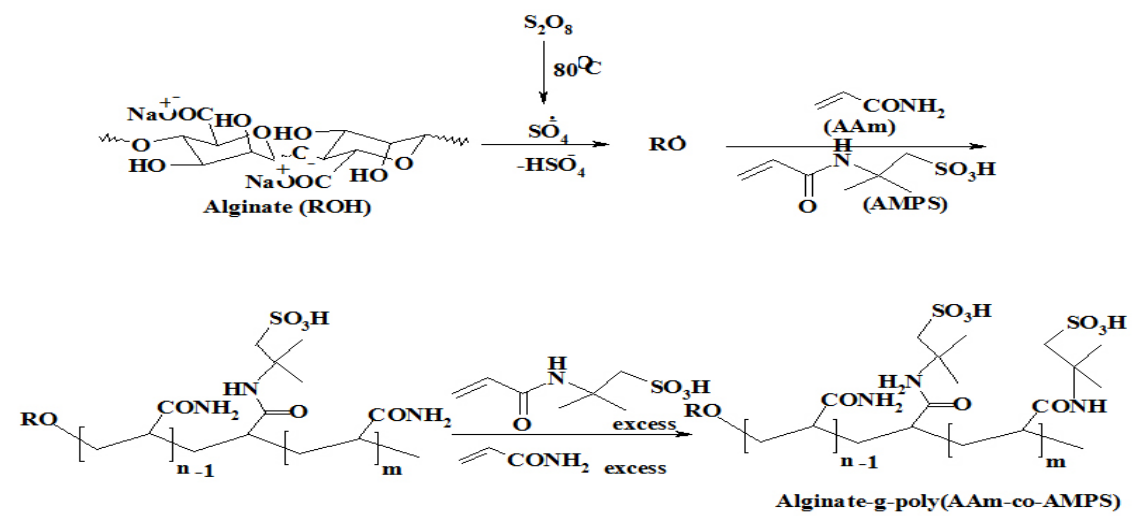

Scheme 1: Proposed mechanistic pathway for synthesis of Alginate-based copolymer



Fig. 1: Plot of Rp versus monomers (AAm-AMPS) concentration

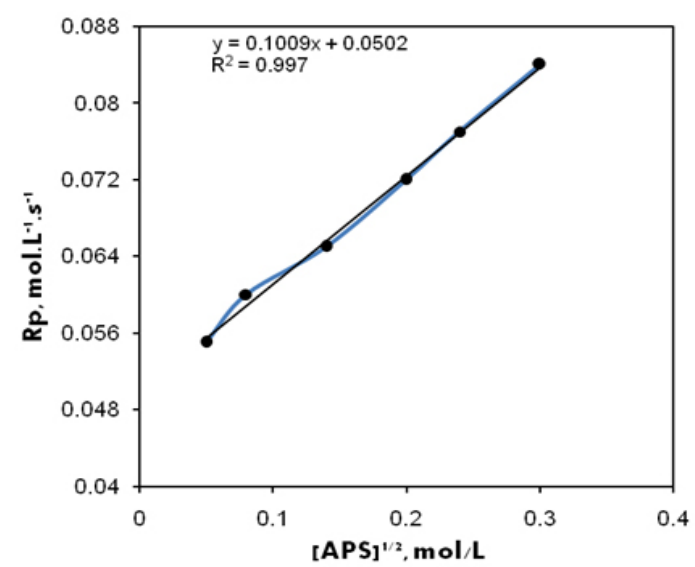

Fig. 2: Plot of Rp versus [APS] ${ }^{1 / 2}$ 
The rates of polymerization (Rp) and graft copolymerization $(\mathrm{Rg})$ may be evaluated as measures of the rate of monomer disappearance by using the following equations ${ }^{7-9}$ :

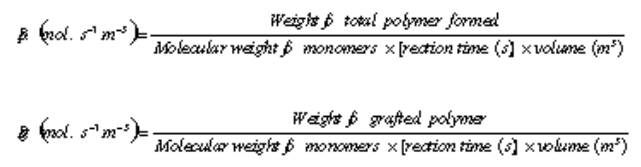

The calculation of $R p$ values may be of significant importance in confirming a proposed



Fig. 3: Plot of Rp versus [alginate] $]^{1 / 2}$ reaction mechanism and kinetics. Therefore, we investigated the relation between rate of graft copolymerization and concentration of APS, AAm,AMPS and alginate. Figures 1-3 show that the plots of Rpversus the monomers concentration, [AAm] + [AMPS], half-order of the initiator concentration, [APS $^{1 / 2}$ and the polysaccharide concentration, [alginate] $]^{1 / 2}$, are linear ${ }^{10}$. This is in agreement with a modified kinetic scheme recently explored for APSinitiated methacrylate grafting onto sago starch. The statement of rate of polymerization according to the scheme is as follows:

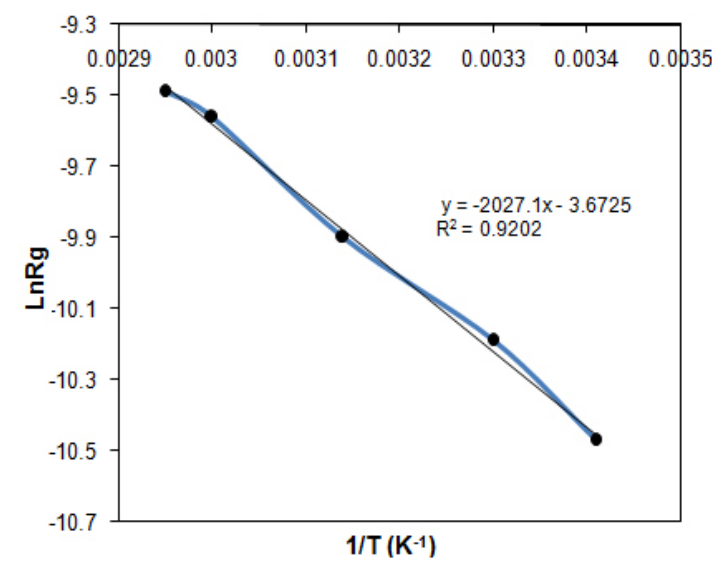

Fig. 4: Plot of LnRg versus 1/T for estimating the activation energy of the graft polymerization reaction
$R p=k_{p}\left(K k_{d} / k_{t}\right)^{1 / 2}[\text { alginate }]^{1 / 2}[A P S]^{1 / 2}[A A C]$ [AMPS]

The coefficient $K$ is the equilibrium constant, $k_{p}, k_{d}$, and $k_{t}$ are the rate constants for propagation, alginate-APS dissociation, and termination reactions, respectively ${ }^{11-13}$. Therefore, we preliminarily conclude that the APS-initiated grafting of acrylamide (AAm) and 2-acrylamido-2methylpropanesulfonic acid (AMPS) onto alginate is also fitted with this kind of rate statement(1618).The overall activation energy (Ea) of the graft polymerization reaction was calculated by using of the Eq. (2) and the slope of the plot LnRg versus1/T (Fig. 4) based on Arrhenius relationship [ $k p=A \exp (-$ $E a / R T)]$. Therefore, Ea for the graft copolymerization was found to be $33.40 \mathrm{~kJ} / \mathrm{mole}$.

\section{CONCLUSION}

To following synthesis of graft copolymer based on alginate by grafting of Simultaneously acrylamide (AAm) and 2-acrylamido-2methylpropanesulfonic acid (AMPS) onto alginate under inert atmosphere, kinetic polymerization was studied. Empirical polymerization rate showed a first-order dependence on the monomers concentration and a half-order dependence on the initiator concentration. According to the slope of $\mathrm{LnRg}$ versus $1 / \mathrm{T}$, the overall activation energy for graft copolymerization reaction was estimated to be $33.40 \mathrm{~kJ} / \mathrm{mol}$. 


\section{REFERENCES}

1. Flory, P. J. In Principles of Polymer Chemistry, Cornell University press, New York: Ithaca (1953).

2. Mi, P.; Ju, X.; Xie, R.; Wu, H.; Ma, J.; Chu, L. Polymer, 51: 1648-1653 (2010).

3. Tang, Q.; Wu, J.; Lin, J. Carbohyd Polym, 73: 10. 315-321 (2008).

4. George, M.; Abraham, T. E. Int J Pharma, 335: 123-129 (2007).

5. Sadeghi, M.; Hosseinzadeh, H. Turk J Chem, 32: 375-388 (2008).

6. R. Soleymani, F. Afshari and B. Hosn., Orient J. Chem., 28(2): 657-668 (2012).

7. Bajpai, A. K.; Giri, A. Carbohydr Polym , 53: 271-278 (2003).

8. Mahdavinia, G. R.; Pourjavadi, A.; Hosseinzadeh, H.; Zohuriaan, M. J. Europ
Polym J, 40: 1399-1407 (2004).

9. Fanta, G. F. In Polymeric Materials Encyclopedia. Salamone, J. C., editor. Florida: CRC Press, Boca Raton, 10: 7901, 8051 (1996).

10. Heinze, T.; Liebert, T. Unconventional Methods in Cellulose Functionalization. Prog. Polym. Sci., 26: 1689-1762 (2001).

11. Fanta, G.F., Doane W.M. In Modified Starches: Properties and Uses; Wurzburg, O.B., Ed.; CRC Press: Boca Raton (Florida), 149-178 (1986).

12. Athawale, V.D.; Rathi, S.C. Func. Polym. 34: 11-17 (1997).

13. Sandle, N.K.; Verma, O.P.S. Varma, I.K. Thermochim. Acta, 115: 189-198 (1987). 